\title{
Sermann Marggraff,
}

\section{Sdiller's und fî̉ruer's}

\author{
Ereundofoftshund.
}





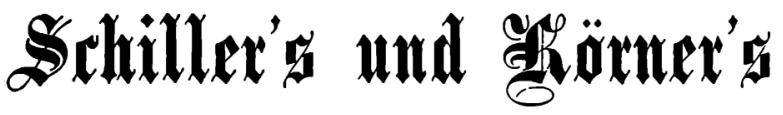

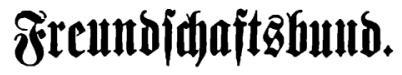

\author{
Ben \\ Sexmann $\mathfrak{M} \mathfrak{a} \mathfrak{a g} \mathfrak{a} \mathfrak{a f f}$
}

\section{sinleitung}

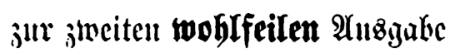

volt

Sd)iller's Briefwed) fel mit ä̈rner.

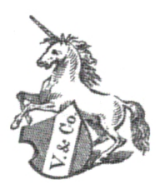

Reipzig,

Scrlag von Beit \& Eontp.

1859. 
